the expression of a cancerpromoting gene called Met.

Two chemotherapies that target pericytes - imatinib and sunitinib - produced similar effects in mice, but their effects on metastasis were suppressed when a Met inhibitor was given simultaneously. The authors suggest that pericyte loss makes tumour blood vessels leaky, which may set in motion events that promote metastasis. Cancer Cell 21, 66-81 (2012)

\section{PHYSICS}

\section{One molecule, one photon}

To harness quantum technology for applications such as computing and cryptography, researchers must develop materials that can emit single photons in response to electrical signals. However, existing approaches require an ultracold environment.

Maximilian Nothaft at the University of Stuttgart in Germany and his colleagues tested phosphorescent iridiumbased organic molecules as the active layer in a lightemitting diode (LED) at room

temperature. They showed

that the molecules could emit photons in response to electrical and laser stimulation. The distribution of the emitted photons suggests that each was emitted by a single molecule.

The authors say that their method should allow for further study of photonemission mechanisms in organic LEDs.

Nature Commun. http://dx.doi. org/10.1038/ncomms 1637 (2012)

\section{CELL BIOLOGY}

\section{Manganese fights deadly toxin}

A toxin produced by certain deadly strains of pathogenic bacteria can be stopped in its tracks by the element manganese.

Shiga toxin - generated by Shigella bacteria and some strains of Escherichia coli
- is shuttled through several organelles in the infected cell and eventually shuts down cellular protein production. Somshuvra Mukhopadhyay and Adam Linstedt at Carnegie Mellon University in Pittsburgh, Pennsylvania, fluorescently tagged the toxin and found that, in cells treated with manganese, the toxin was rerouted to the cell's degradative compartment and destroyed. Manganese targets a protein called GPP130 which is normally required for the trafficking of the toxin - preventing the toxin from binding to it.

Mice injected with the toxin and treated with manganese stayed healthy throughout the six-day study, whereas untreated mice died within four days.

Science 335, 332-335 (2012)

$$
\text { ECOLOGY }
$$

\section{Ready for the toxic toads}

Exposure to an exotic plant seems to have pre-adapted a native Australian lizard to the toxins of an invasive animal.

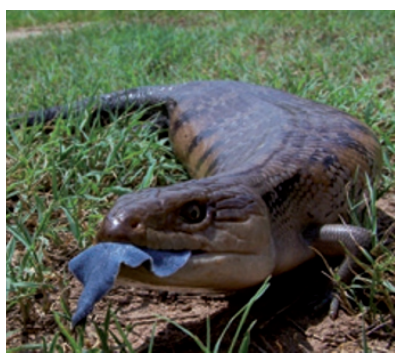

The American cane toad (Rhinella marina), an exotic introduced to Australia within the past century, is generally toxic to native predators. But Richard Shine and his colleagues at the University of Sydney observed that bluetongue skinks (Tiliqua scincoides; pictured) in some areas can tolerate the toad's toxins. The toxins are similar to those produced by another exotic species, the Madagascan 'mother of millions' plant (Bryophyllum spp.).

The authors tested the resistance of skinks from

COMMUNITY CHOICE

The most viewed papers in science

CLIMATE CHANGE

\title{
Warming, but not as much
}

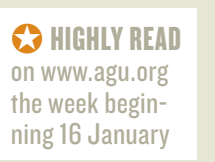

The climate system may be less sensitive to greenhouse-gas warming than many models have predicted.

Nathan Gillett and his co-workers at Environment Canada in Victoria, British Columbia, analysed how well the latest Canadian Earth System Model tracked temperature changes attributable to volcanoes, man-made aerosols and rising greenhouse-gas emissions. They adjusted the model using temperature records from 1851 to $2010-60$ years of data more than most previous analyses. The model predicted a short-term increase of $1.3-1.8^{\circ} \mathrm{C}$ for a doubling of atmospheric carbon dioxide levels, which is low in the range of estimates from previous forecasts.

Under various scenarios, the authors' model forecasts warming of $1.2-4.3^{\circ} \mathrm{C}$ by the end of the century compared with pre-industrial times.

Geophys. Res. Lett. http://dx.doi.org/10.1029/2011GL050226 (2012)

various regions of Australia to either the toad or plant toxin. They found that skinks from areas where the plant is abundant were better able to tolerate both. Moreover, skinks readily eat both the plants and the toads. The findings suggest that the plants have selected for skinks that could tolerate the toad toxins. Am. Nat. http://dx.doi. org/10.1086/664184 (2012)

\section{NEURODEVELOPMENT}

\section{Mutation and} infection to blame

A combination of genetic and environmental factors may act synergistically to boost the risk of certain neurodevelopmental disorders.

In humans, mutations in NURR1 - a gene vital for the normal development of neurons that produce a neurotransmitter called dopamine - are thought to slightly raise the risk of neurodevelopmental disorders. The risk is similarly increased by infection in the mother during pregnancy. To test the combined effect of these two factors, Urs Meyer at the Swiss
Federal Institute of Technology in Zurich and his colleagues activated the immune system of pregnant mice that had only one copy of the Nurrl gene.

They found that dopaminergic development in key parts of the brain was impaired in Nurr1-deficient pups born to immuneactivated mothers. As adults, these mice were unable to sustain or shift attention normally, a characteristic of neurodevelopmental diseases such as schizophrenia and attention-deficit hyperactivity disorder.

J. Neurosci. 32, 436-451 (2012) 